\title{
Evocando elementos extramusicais do Minho na aula de piano: Repertório contemporâneo português em contexto
}

\begin{abstract}
RESUMO
O projeto que se apresenta propôs-se a explorar os efeitos do recurso a elementos extramusicais do Minho na abordagem pedagógica de repertório contemporâneo português, numa escola de música de ensino artístico especializado localizada nessa região. A fim de evitar a descontextualização da escola de música, alheia ao seu local e ao seu tempo, o projeto procurou aliar o europeu, o nacional e, sobretudo, o local, por entre sonoridades vanguardistas contextualizadas pelos significados extramusicais que thes serviram de inspiração. Combinando metodologias de investigação-ação e estudo de caso, o projeto envolveu a observação detalhada do processo de aprendizagem de peças evocativas de elementos extramusicais minhotos do compositor contemporâneo português Amílcar Vasques-Dias, por dois alunos de piano do ensino secundário. A metodologia incluiu (1) a análise musical das peças focada nos elementos extramusicais, para a fase do planeamento; e (2) aulas centradas no cruzamento entre o musical e o extramusical e ainda um concerto final, para a fase da intervenção. Os resultados indicaram que os elementos extramusicais promoveram a 'compreensão' (ou apreciação) da linguagem musical contemporânea por parte dos alunos intervencionados, desempenhando assim uma função de mediação técnica, interpretada segundo Albèra (2007). Ademais, contribuíram para a melhoria de aspetos técnicos, interpretativos e expressivos. Por outro lado, o recurso a estes elementos ajudou a promover a valorização da cultura regional, tendo ocorrido inclusivamente um caso de contextualização curricular, em que os elementos minhotos se aproximaram das vivências pessoais da aluna.
\end{abstract}

\author{
Isabel Romero ${ }^{i}$ \\ Escola Artística de \\ Dança do Conservatório \\ Nacional, Portugal \\ Vera Fonte ${ }^{\mathrm{i} i}$ \\ CEHUM, Universidade do \\ Minho, Portugal \\ Luís Pipa ${ }^{\text {iii }}$ \\ CEHUM, Universidade do \\ Minho, Portugal
}

Palavras-chave: Repertório contemporâneo português; Referências extramusicais; Significado cultural; Currículo contextualizado; Metáfora no ensino 


\section{INTRODUÇÃO}

O presente projeto teve como fundamento dois princípios estruturantes da atuação educativa e cultural - o da articulação entre escola de música e comunidade e o da valorização do património cultural - no contexto micro e unidisciplinar da aula de piano. 0 primeiro princípio compreende o incentivo ao desenvolvimento de laços entre a escola de música, a comunidade local e a comunidade artística nacional. 0 segundo encontra expressão jurídica no texto constitucional, incumbindo o Estado de "promover a salvaguarda e a valorização do património cultural, tornando-o elemento vivificador da identidade cultural comum" (art.o 78. ․, n.․ 2, al. c da Constituição da República Portuguesa). 0 repertório português e os elementos extramusicais minhotos, que ganham especial protagonismo neste projeto, oscilam entre os dois princípios.

Num cruzamento entre o musical e o extramusical, pretendeu-se explorar o potencial cosmopolita e multicultural da cultura de fronteira (Santos, 1993), aliando-se o europeu (através da herança ocidental da linguagem musical erudita) ao nacional (ao valorizar-se o património musical erudito português, mesmo na ausência de um denominador comum) e ao local (através dos elementos extramusicais ligados ao ruralismo minhoto).

Assim, o presente projeto de investigação propôs-se a compreender os efeitos do recurso aos elementos extramusicais do Minho na abordagem de repertório contemporâneo português no ensino de piano. Em torno de dois eixos fundamentais - a metáfora no ensino da música e a contextualização cultural (inspirado no conceito "significado cultural" de Dillon, 2007) - a análise focou-se nos seguintes temas: processo de aprendizagem das obras, dimensão criativa e dimensão performativa, para o primeiro eixo; e identificação pessoal dos alunos com os elementos extramusicais locais, para o segundo eixo.

Na secção que se seguirá, passar-se-á em revista os principais conceitos teóricos que enformaram o projeto.

\section{ENQUANDRAMENTO TEÓRICO}

O princípio da articulação entre escola de música e comunidade preconiza o estabelecimento de pontes entre a escola, o "lugar" e o "tempo" onde esta se desenvolve. Pretende-se aproveitar, de um lado, a capacidade da escola de reunir gerações, qual sociedade microscópica, e de criar experiências conjuntas significativas. Do outro, tirar proveito da riqueza que traz a expressão artística, em especial a música, na sua ligação direta às emoções, enquanto "essência encarnada e inteligível do sentimento" (Liszt in Grout \& Palisca, 1988, p. 575). A escola de música terá condições para estabelecer uma ligação dialética com a comunidade, contribuindo duplamente para a sua valorização: dela poderá ressaltar os pontos fortes, bebendo da sua fonte o sentido, e ainda contribuir para a sua riqueza cultural, ao monitorizar novas manifestações artísticas.

Radicar a escola de música no local onde se insere faz remissão ao conceito de "significado cultural" (cultural meaning) de Dillon (2007), isto é, a expressão e a interação recíproca que tanto o produto artístico quanto o criador têm com a comunidade ou, por outras palavras, a natureza da prática musical enquanto produto de uma comunidade. 0 conceito "significado cultural" pode ser conduzido ao "currículo contextualizado" - a aproximação 
dos processos de ensino-aprendizagem às realidades concretas dos alunos quando este é olhado sob o prisma do local onde as aprendizagens ocorrem (Fernandes et al., 2013).

0 estabelecimento dessa ponte parece ser especialmente relevante em tempos de intensa globalização cultural. Embora a receção local das mensagens, símbolos e ideias globais não seja um processo passivo, esta ocorre num quotidiano confuso, contraditório, pleno de novas e discrepantes informações, o que pode condicionar o poder criativo das reinterpretações (Winter, 2003). As comunidades, em resposta à quantidade e síncrese das mensagens da cultura global e à erosão do Estado-nação no contexto da aldeia global, adotam medidas de valorização do património local (Moreira, 2006).

As escolas de música, herdeiras do legado oitocentista, parecem tender a colocar o foco no repertório clássico e romântico (Green, 2002; Palheiros, 1999). Este foco, em conjunto com a proliferação de currículos multiculturais e a promoção das tecnologias digitais, é a manifestação, segundo Bates (2014), do cosmopolitismo tradicional na educação musical, isto é, aquele que tende a privilegiar uma elite cultural e urbana em detrimento de culturas locais. 0 objetivo da educação musical cosmopolita aparenta ter como missão, na opinião do autor, "libertar as crianças das perspetivas e modos de vida locais" (Bates, 2014, p. 310), o que entra em colisão com o que deveria ser o núcleo essencial do cosmopolitismo - uma postura moral de preocupação com o bem-estar de todos os indivíduos. De modo a evitar uma "colonização cultural" dos povos e dos locais, e a conservar os fundamentos do cosmopolitismo, o autor apela ao reconhecimento da importância das práticas musicais locais (Bates, 2014).

A preocupação pelas manifestações musicais locais é ainda um dos pilares fundamentais do método de ensino desenvolvido por Zoltan Kodály, assente na importância da canção tradicional na educação musical. 0 contacto com a "linguagem materna musical" e, assim, com a "alma local", conduz ao encontro do indivíduo consigo mesmo, no novelo caótico que caracteriza a modernidade (Kodály in Cruz, 1998, p. 6). Villa-Lobos e LopesGraça foram também eles defensores da importância da música tradicional enquanto promotora da identidade coletiva, o primeiro na qualidade de cabecilha do grande projeto nacional do canto orfeónico (do governo Vargas) (Lobos, 2010), o segundo enquanto maestro do coro da Academia de Amadores de Música, cujo repertório incluía as Canções Regionais Portuguesas, com motivações políticas bem distantes do primeiro (Carvalho, 2010).

Atualmente, são desenvolvidos em Portugal inúmeros projetos de intervenção pedagógica incidentes no património musical rural, como é exemplo o projeto dos sargaceiros da Apúlia e da orquestra de cordas desenvolvido por Brito e Vieira (2014), no qual foram estudados (sem recurso à partitura) temas provenientes da tradição oral. Alguns dos alunos participantes chegaram a concluir que todos eram "povo" e que a música tradicional não estava assim tão afastada da sua esfera social como à partida pensariam.

Com o propósito de divulgação e preservação da cultura musical portuguesa, o projeto pareSeres da Terra (Ribeiro, 2017), integrado no projeto educativo do Conservatório do Vale do Sousa, tem vindo a desenvolver atividades - conferências, workshops e concertos - que reúnem elementos internos e externos à escola. As edições anuais, que remontam já a 2007, são dedicadas desde ao fado e à música tradicional do Vale do Sousa 
até a nomes como Zeca Afonso, Sérgio Godinho, Fausto, entre outros (Ribeiro, 2017).

Quanto ao papel da educação musical no fortalecimento da coesão da comunidade local, vale a pena referir o estudo de Spring (2016), no qual foram analisados, sob o prisma da relação com o 'local', testemunhos de quatro professores de música, com atividade em zonas rurais do Condado de Simcoe, no Canadá. Foi pedido aos professores que apresentassem duas metáforas representativas da sua prática pedagógica - uma musical e outra literária - e, a partir delas, desenvolvessem e descrevessem as suas histórias e experiências. A escolha das metáforas, e as narrativas descritivas que as acompanharam, foi reveladora do poder do educador musical enquanto intermediário, que fortalece, através das experiências musicais, sentimentos de pertença da comunidade escolar com a área rural. No que toca às escolhas musicais, evidenciaram igualmente o poder emocional e social das apresentações públicas, sobretudo quando enquadradas na cultura local (Spring, 2016).

Já sobre a cultura portuguesa, e sua difícil delimitação material, Santos (1993) alega que esta não tem conteúdo, apenas forma, e de que essa forma é a fronteira. Segundo o autor, o a-centrismo da cultura portuguesa deve-se em grande medida ao seu "déficit de identidade pela diferenciação", por nunca se ter conseguido diferenciar totalmente das culturas exteriores, e pelo seu "déficit de identidade pela homogeneidade", por se caracterizar por uma grande heterogeneidade interna (Santos, 1993, p. 47). Assim, esta condição de fronteira, de semiperiferia, confere à cultura portuguesa um natural potencial ao cosmopolitismo, por nenhum localismo se destacar suficientemente dos outros para se afirmar como nacional. A zona fronteiriça é, nas suas palavras, "uma zona híbrida, babélica, onde os contactos se pulverizam e se ordenam segundo micro-hierarquias pouco suscetíveis de globalização" (Santos, 1993, p. 49).

A condição de periferia seria a principal causa da subalternização da música portuguesa em relação à música europeia, segundo Vargas. A música portuguesa estaria presa à racionalidade central, qual refém do local de enunciação detentor do "poder de declarar e institucionalizar o local próximo como global e o local afastado como local" (Vargas, 2007, p. 60), não conseguindo, por outro lado, ser suficientemente diferente para apresentar características do "outro". Nos anos 40, Lopes-Graça reitera que é o “'ar de família', o tal denominador comum (...), que falta na moderna produção musical portuguesa, e que, com muita razão, faz desconfiar o público da batida expressão 'música portuguesa', que ele sente não corresponder a nenhuma realidade ético-estética objetiva" (Graça, 1989, p. 29).

No que toca à ponte entre o ensino formal de música e o tempo, a sua concretização passa necessariamente por explorar o campo da música contemporânea erudita. Este repertório, por sinal extenso, é, no entanto, incapaz de singrar num público vasto, apesar da sua atualidade. Albèra (2007, s.p.) defende que é imperativa a presença de uma mediação social e intelectual - através da comunicação social, dos meios educativos, entre outros - que permita às linguagens contemporâneas existirem socialmente. É através das relações complexas que mantêm com a realidade que "as obras de arte podem falar ${ }^{1 \text { ", }}$, uma vez que, sem contexto, perdem o seu sentido e a sua necessidade. Em contrapartida, Foucault (in Foucault et al., 1985) alega que a condição única da música contemporânea se deve ao seu próprio discurso musical, que se despoja de qualquer tipo de pistas, sinais, esquemas

1. Itálico dos autores 
ou estruturas repetitivas que orientem a audição, exigindo dos ouvintes uma posição de risco permanente.

Neste projeto, a linguagem musical contemporânea apareceu cruzada com o extramusical, numa simbiose de dimensões sensitivas. Durante o processo de ensino-aprendizagem, esta característica implicou o recurso constante à metáfora, que se afigura como "um processo privilegiado de articulação entre a experiência sensorial e a expressão musical, contrapondose à linguagem literal e resultando numa forma externa, criativa, de representação de um processo interno" (Ruiz \& Vieira, 2017, p. 14). A metáfora é convencionalmente estruturada em três elementos: o tenor (o tema que despoletou a metáfora), o veículo (a analogia) e o fundamento (as características que o tenor e o veículo possuem em comum) (Wade, 2017). A metáfora não se restringirá à analogia: será uma forma de dizer que algo é igual a outro elemento, indo para além da mera semelhança (Wade, 2017).

Enquanto ferramenta de transmissão de uma ideia, a metáfora pode servir ora um propósito técnico (enquanto facilitador da compreensão de um aspeto motor) ora um propósito expressivo (emocional ou estético) (Schippers, 2006). No domínio interpretativo, ajuda a atribuir significado ao pensamento musical e alarga a paleta expressiva do músico; no domínio técnico, estimula a experiência sensoriomotora e promove a memorização e a interiorização (Wolfe, 2019).

\section{METODOLOGIA}

O projeto de investigação foi operacionalizado no contexto da prática de ensino supervisionada do Mestrado em Ensino de Música da Universidade do Minho, que teve lugar numa escola de ensino especializado da música na cidade de Braga. Surgiu em resposta a um problema verificado durante as aulas, designadamente a ausência de obras contemporâneas portuguesas de entre o repertório estudado pelos alunos e o seu relativo desconhecimento tanto de repertório português como de contemporâneo.

No quadro de uma investigação-ação, adotou-se o método qualitativo, num procedimento baseado na metodologia de estudo de caso. 0 projeto teve como participantes dois alunos do ensino secundário - a Isolda e o Leonardo (nomes fictícios), de 15 e 16 anos, respetivamente -, alunos cuja participação no projeto se fundamentou, em primeiro lugar, pelo facto de frequentarem o ensino secundário, apresentando maior preparação para a abordagem de repertório contemporâneo; e, em segundo, por critérios de gestão de programa, ficando de parte uma aluna finalista em fase de preparação de provas de ingresso para o ensino superior.

Assim, foi proposto aos alunos o estudo de peças evocativas de elementos do Minho do ciclo Lume de chão - Tecido de memórias e afectos (2004) do compositor Amílcar Vasques-Dias (1945 -), nomeadamente Cerejas-Pão, à primeira aluna, e Linho e Fiar, ao segundo aluno. 0 processo de atribuição das peças passou por duas fases: recolha de repertório contemporâneo português com referências extramusicais portuguesas (uma vez que não estava decidido à partida que seriam referências do Minho) e, depois de selecionada a obra, a escolha das peças propriamente dita.

A preferência pela obra Lume de chão - Tecido de memórias e afectos deveu-se naturalmente ao facto de reunir a particularidade de evocar elementos do Minho, as memórias de infância do compositor na casa da avó de Badim, numa boa parte do ciclo. As peças que evocavam elementos do 
Minho tinham como títulos Acender o lume, Eira do Outeiro, Ao lume, Alçapão, Cerejas-Pão, Espadelar, Assedar, Fiar, Linho e Tear-Tecer. Sabendo de antemão que se pretendia incluir uma peça relacionada com o linho, as três peças foram escolhidas tendo em conta a adequação à personalidade do aluno, a variedade das referências e critérios técnicos. A Cerejas-Pão foi a primeira a ser atribuída, uma vez que se adequava perfeitamente ao estilo performativo e personalidade da Isolda. 0 linho ficou assim reservado ao Leonardo. Das cinco peças do ciclo, excluiu-se logo Tear-Tecer pela dificuldade técnica. Fiar era aquela que parecia estar mais em sintonia com o estilo do aluno. No entanto, como a peça era muito curta, decidiu-se acrescentar mais uma, a Linho, que congregava nela vários momentos do processo de produção do linho e não se cingia a uma determinada etapa.

A investigação dividiu-se em duas fases: o planeamento - análise das peças escolhidas com enfoque nos elementos extramusicais do Minho que lhes serviram de inspiração; e a intervenção - análise da influência do recurso pedagógico aos elementos extramusicais no processo de aprendizagem das obras.

Os momentos da investigação foram avaliados com recurso a diversos instrumentos de recolha de dados. Para o planeamento, realizou-se uma entrevista semiestruturada ao compositor, em conjunto com a análise da partitura. Quanto à intervenção, os instrumentos passaram pelas gravações áudio ou vídeo das aulas e do concerto final, pelas notas de campo e pelas entrevistas semiestruturadas pós-interventivas aos alunos.

0 tratamento dos dados da fase da intervenção procurou conjugar os dados heterogéneos obtidos nos instrumentos de recolha. Assumindo um carácter qualitativo, a análise foi descritiva e interpretativa. As entrevistas e comentários dos participantes durante as aulas foram analisados de acordo com o método da análise temática (Clarke \& Braun, 2015). Os temas identificados foram previamente estabelecidos e baseados nas perguntas de investigação inicialmente colocadas.

\subsection{IMPLEMENTAÇÃO DA AÇÃO}

A fase da intervenção teve uma duração aproximada de três meses, culminando numa apresentação pública, comentada pelos próprios alunos participantes, no "Concerto de Música Portuguesa" organizado pela escola. As apresentações tiveram como pano de fundo imagens dos elementos minhotos, escolhidas pelos alunos em concertação com o professor. Durante o processo de aprendizagem, decorreu no Museu Nogueira da Silva, de Braga, o evento da publicação da partitura oficial da obra e do CD Viagens na minha terra, com o protagonismo da pianista Joana Gama e comentários do compositor Amílcar Vasques-Dias.

As planificações das aulas pretenderam promover o estabelecimento das pontes entre o musical e o extramusical propostas pelo compositor, através da análise do texto musical e dos elementos minhotos, da procura pelo aluno de opções interpretativas consoante as referências do compositor e, por fim, da criação pelo aluno de outras pontes inspiradas nessas referências.

As estratégias oscilaram entre o ensino tradicional - centrado no professor e na transferência do conhecimento - e a escola ativa - centrada no interesse do aluno e, a partir daí, na criação de conhecimento (vide Freire, 1986). Do ensino tradicional, foram utilizados o método expositivo e o método demonstrativo, na forma de explicação verbal, exibição de filmes e 
imagens e exemplificação. Da escola ativa, foram utilizadas estratégias como a colocação de perguntas - sobre a análise, notação, sobre a natureza das referências, sobre o imaginário musical, sobre as perceções pessoais das peças estudadas, sobre opções interpretativas, entre outras -, a delineação de algumas tarefas de pesquisa em casa, a contribuição dos alunos na construção da narrativa musical metafórica, a participação ativa dos alunos no concerto final - nomeadamente na escolha das imagens, em concertação com o professor, e nos comentários das peças - e, ainda, um momento de improvisação da Isolda com motivos da obra.

O período inicial da intervenção foi caracterizado por uma abordagem essencialmente centrada em questões de notação musical e de técnica, na fase aqui designada por "O texto musical". As referências extramusicais do Minho foram introduzidas em maio, marcando o início da fase "Os elementos do Minho". Para uma melhor articulação com as necessidades curriculares e gestão dos conteúdos, o projeto compôs-se sobretudo de fragmentos de aulas, e não aulas inteiras. Apresenta-se aqui a calendarização do processo e a minutagem dos segmentos de aulas. As datas sublinhadas consistiram nas únicas aulas que foram geridas pelo mestrando na sua totalidade.

\begin{tabular}{|c|c|c|c|c|}
\hline & O texto musical & $\begin{array}{l}\text { Os elementos do } \\
\text { Minho }\end{array}$ & $\begin{array}{l}\text { Ensaio para o } \\
\text { concerto }\end{array}$ & Concerto \\
\hline Isolda & $\begin{array}{l}\text { 07/03/19 (20') } \\
02 / 05 / 19\left(10^{\prime}\right)\end{array}$ & $\begin{array}{l}16 / 05 / 19\left(50^{\prime}\right) \\
23 / 05 / 19\left(20^{\prime}\right) \\
30 / 05 / 19\left(15^{\prime}\right)\end{array}$ & 03/06/19 & $05 / 06 / 19$ \\
\hline Leonardo & $\begin{array}{l}07 / 03 / 19\left(20^{\prime}\right) \\
14 / 03 / 19\left(15^{\prime}\right) \\
21 / 03 / 19\left(15^{\prime}\right) \\
02 / 05 / 19\left(40^{\prime}\right)\end{array}$ & $\begin{array}{l}\frac{09 / 05 / 19\left(50^{\prime}\right)}{16 / 05 / 19\left(25^{\prime}\right)} \\
23 / 05 / 19\left(20^{\prime}\right) \\
30 / 05 / 19\left(25^{\prime}\right)\end{array}$ & 03/06/19 & $05 / 06 / 19$ \\
\hline
\end{tabular}

\subsection{DESCRIÇÃO DAS PEÇAS ESCOLHIDAS}

A descrição das três peças escolhidas baseia-se na análise realizada na fase do planeamento do projeto. Como já adiantado, integram o ciclo Lume de chão - Tecido de memórias e afectos, conjunto de treze pequenas peças que pretende fazer a ligação entre a lareira do Minho, ligeiramente alteada, e o lume de chão alentejano. Nele sucedem-se recortes de "memórias e afetos" associados a duas regiões portuguesas: o Minho, a terra de origem e infância do compositor, e o Alentejo, a região onde reside atualmente (depois de um período de catorze anos na Holanda). As peças escolhidas - Cerejas-Pão, Linho e Fiar - são todas elas alusivas ao Minho.

Cerejas-Pão é uma lembrança, com saudade, da avó a comer cerejas com pão de milho ao pé da cerejeira do tanque de sua casa. Estas cerejas assemelham-se, na verdade, às ginjas, se se atentar à descrição do compositor, por serem "maiores", "mais bolachudas" e com uma "parte branca" (Amílcar Vasques-Dias, comunicação pessoal, 2 de abril de 2019). 0 pão de milho era produzido "à moda antiga" no forno a lenha. Esta lembrança vem envolta de um ambiente de carinho e de ternura, que se concretizará necessariamente na "delicadeza na maneira de afagar as teclas, as notas, as apogiaturas, o som..." (ibidem).

Os desenhos no registo agudo são a expressão da "criança que olha e vê aquelas 'coisinhas' penduradas" (ibidem). No meio da peça, num 
movimento de crescendo climático, quase cadenciado, o menino sobe ao telhado com o intuito de apanhar as cerejas na copa da árvore. Os motivos descendentes que se seguem ilustram o movimento de apanhar as cerejas ou os raminhos da cerejeira. Na coda, faz-se uma pequena alusão ao linho, na forma do espadelar e do assedar, semelhante à utilizada na peça Linho.

As peças Linho e Fiar evocam várias fases do processo rural de produção do linho. Tendo como fim eliminar os vários vestígios de caule da planta até ao fio, o processo compõe-se de etapas como semear, colher, ripar, molhar, malhar, moer, espadelar, assedar, fiar, ensarilhar, dobar e tecer, intercaladas por outras, como lavar e secar (Bernardo, 2010). As retratadas nas duas peças escolhidas - espadelar, assedar, fiar, dobar - são todas elas desempenhadas por mulheres, apetrechadas de instrumentos próprios.

Na peça Linho, representa-se o fio de linho - "uma distância grande entre duas notas (dois sons!), mas tocadas simultaneamente..." (ibidem), a meio tom de distância e ainda separadas por duas oitavas, num registo agudo -, o acumular dos fios, a inversão do processo - depois de tocado o acorde, o intérprete vai soltando gradualmente as notas das teclas - e o espadelar representado por um acorde denso no ataque que deixa retidas apenas duas notas, num movimento rápido que traduz o momento em que as impurezas saltam e o linho fica mais limpo.

A peça Fiar é dedicada à fiadeira que, com a roca debaixo do braço esquerdo e o fuso na mão direita, transforma o linho em fios, enrolando o fio com os dedos. 0 momento principal da peça é a expressão musical do movimento do fiar, num continuum na mão direita, acompanhado na mão esquerda pelo cantarolar da fiadeira, que divaga durante esta tarefa repetitiva e mecânica. "Como a coisa está na calha, já está em andamento, então o que fazer? Não precisa de estar a pensar e começa a cantar. Ela estará a cantar aquilo meio desafinado. É mais o estar entretida" (Ibidem).

Na secção inicial da peça, o compositor evoca o assedar (o primeiro gesto, em representação do linho a passar pelo sedeiro, um pente com dentes finos de aço), o movimento contínuo dos dedos a molhar e esticar o fio (através de notas em stacatto) e, num breve relance, a dobadoira.

\section{RESULTADOS}

Serão apresentados nesta secção os resultados provenientes dos dados heterogéneos recolhidos - observação das aulas e do concerto final e entrevistas semiestruturadas pós-interventivas aos alunos -, aqui organizados de acordo com os cinco temas que serviram de base para a análise temática: (1) evolução da motivação ao longo do processo de aprendizagem das peças; (2) prestação no concerto final; (3) identificação e criação de referências extramusicais; (4) influência das referências extramusicais na interpretação; (5) identificação pessoal com os elementos minhotos. Os quatro primeiros temas integram o já referido eixo da metáfora no ensino da música, ao passo que o último integra o eixo da contextualização cultural. Para cada tema, serão contrapostos os resultados dos dois alunos envolvidos. 
Começando pelo processo de aprendizagem, o primeiro tema do eixo da metáfora no ensino da música, os dois alunos envolvidos demonstraram ter sentido um crescendo de motivação. Segundo os testemunhos dados nas entrevistas, ambos partiram de uma primeira reação de estranheza em relação às peças, repletas de "dissonâncias", para um contínuo aumento de interesse e gosto na aprendizagem. Segundo o Leonardo, as peças "começaram a entrar" já que, ao familiarizar-se com a linguagem musical e os elementos extramusicais, percebeu que "até gostava", "libertando-se cada vez mais". A Isolda referiu por várias vezes a importância da "contextualização da peça" para atribuir sentido ao texto, uma vez que inicialmente estava "a tocar notas à toa" e que "é sempre melhor quando se sabe 'do que é que se está a falar'”. Por ser uma linguagem diferente, disse que o mais difícil era "fazer com que certas melodias soassem melódicas", que soassem "bem todas juntas", por serem "notas que, se calhar, não teriam um percurso melódico muito usual". Os elementos extramusicais parecem, assim, ter ajudado a conferir sentido a linhas musicais que, num primeiro momento, poderiam ser estranhas a ouvidos menos experientes. No caso do Leonardo, para além do seu veredicto na entrevista, foi notória a evolução do interesse ao longo das aulas, progredindo de um certo alheamento para uma maior proatividade e entusiasmo, sobretudo nos ensaios finais.

No que toca à prestação no concerto final, o resultado revelou ser muito satisfatório. Os dois alunos em questão estavam bastante descontraídos - como se pôde constatar tanto da observação do concerto como do seu testemunho nas entrevistas - e tocaram de forma muito expressiva. Dos pais, como se soube através das entrevistas aos alunos, a reação foi também positiva, tendo uma mãe ressalvado o contributo das explicações iniciais dos alunos para uma melhor assimilação e fruição das obras.

0 terceiro tema em análise reporta-se à identificação das referências extramusicais - isto é, aos elementos que foram identificados pelos alunos depois de serem descritos sem menção explícita ao local da partitura onde eram representados - e à criação autónoma de referências, inspiradas nas ideias do compositor, para determinados momentos das obras. Foram identificados nas aulas os elementos "fiar", "assedar" e "espadelar" no caso do Leonardo, e o elemento "espadelar", no caso da Isolda. A identificação é provavelmente devida ao facto de se tratar de representações de movimentos desempenhados por humanos, cuja ligação era dada a entender através do próprio desenho do texto musical. No que respeita à criação de referências, a Isolda sugeriu intuitivamente o "momento de estranheza" para o compasso anterior à coda, quando a mão esquerda se junta aos motivos descendentes dos raminhos de cereja, no registo grave, criando assim uma cor harmónica totalmente diferente. Já o Leonardo, em relação aos sforzandos finais da peça Fiar, sugeriu, depois de pensar em casa numa possível referência ligada ao linho, imaginar-se novamente o espadelar - referência já utilizada pelo compositor na peça Linho - na mão esquerda, que estaria, segundo o que se interpretou, em contraposição com o fiar da mão direita. Esta última acabou por necessitar de maior ponderação, provavelmente por se situar longe da realidade concreta do aluno. Não surtiu grande influência na interpretação, talvez por ter sido criada numa fase mais adiantada, após já terem sido tomadas algumas opções performativas.

Apresenta-se em quarto lugar o tema da influência performativa dos elementos extramusicais, aqui alvo de maior extensão na análise. Os efeitos foram avaliados através da observação do professor-investigador e 
dos testemunhos dos alunos nas entrevistas. Pareceu verificar-se que o efeito geral foi positivo, tanto ao nível expressivo (a maioria das referências) quanto ao nível técnico, como se irá detalhar.

Em relação ao efeito expressivo, a Isolda explicou durante a entrevista que tentou transmitir as ideias do compositor imaginando-as ela mesma "na cabeça", durante o estudo e durante a apresentação. Durante as aulas, a aluna sugeriu autonomamente algumas opções de interpretação consoante os elementos que lhe eram apresentados. Disto são exemplos, no elemento das "cerejas", a sugestão de se tocar a mão direita mais leve e articulada; no elemento do "menino a tirar ramos de cerejas da árvore", a sugestão de se realçar os grupos de notas, para melhor retratar os ramos (que podiam ser de duas ou de três cerejas), e de se tocar a passagem com as duas mãos, para salientar a separação das notas (tal qual as cerejas); e, ainda, no "momento de estranheza", que espontaneamente foi tocado com um timbre diferente, a sugestão de se fazer uma ligeira respiração entre o momento anterior. Já quanto ao Leonardo, como observado no decurso das aulas, temos o exemplo do elemento do "acumular dos fios", em reação ao qual tocou instintivamente com um movimento rotativo para cada nota; e do canto da fiadeira, que tornou a linha da mão esquerda mais expressiva. Ao nível técnico, dá-se conta do exemplo do elemento do "espadelar" enquanto facilitador da compreensão do movimento técnico (tocar e relaxar logo de seguida), como testemunhado pelo próprio aluno durante a entrevista, ao dizer que o ajudara a ficar "mais confortável numa parte em que não estava tão confortável".

Contudo, apesar dos exemplos acima mencionados, houve variações na compreensão e tradução das metáforas na performance, com maior ou menor necessidade de mediação de outras indicações complementares, ou até mesmo incompreensão. Assim, os elementos extramusicais, olhados sob o prisma da sua correlação ao efeito performativo, podem ser divididos segundo o critério da aproximação (ou não) a metáforas comummente utilizadas no meio musical e o subcritério da dicotomia entre abstrato (fosse na natureza do elemento, incluindo as emoções, fosse no modo como estavam traduzidos no texto musical) e concreto. Os elementos mais próximos de metáforas comummente utilizadas no meio musical - como o "canto das fiadeiras" (cantabile) e emoções como o "momento de estranheza" e "nostalgia" - tendiam a ser eficazes e facilmente compreendidos, independentemente de serem abstratos ou concretos.

Já quanto aos elementos que não se aproximavam de metáforas comummente utilizadas no meio musical, houve variações segundo o subcritério acima referido. Regra geral, as metáforas que se revelaram mais difíceis de compreensão foram aquelas que se situavam no domínio abstrato, nomeadamente os "fios de linho" e a "antecipação furtiva da dobadoira". Os "fios de linho" - abstratos sobretudo no modo como estavam refletidos na partitura - acabaram por ser muito bem interpretados, mas apenas depois de serem dadas várias indicações concretas ao nível da execução (como tocar com as pontas dos dedos, timbrar mais o soprano e tocar menos "nota a nota", menos tenuto), acrescentando-se a isso o contributo muito importante da metáfora "mais aéreo" (que, por sua vez, se aproxima de metáforas comuns no meio musical). A referência da "antecipação furtiva da dobadoira" revelou-se demasiado elaborada, não surtindo efeito na interpretação musical. Já os elementos situados no subcritério do concreto - como, por exemplo, "cerejeira" e "cerejas", "espadelar", "subir ao telhado" - foram bastante bem compreendidos e assimilados. 


\subsection{SEGUNDO EIXO: CONTEXTUALIZAÇÃO CULTURAL}

Quanto ao segundo eixo (e último tema), relativo à identificação pessoal com os elementos minhotos, os resultados variaram. Segundo o relatado na entrevista, a Isolda já conhecia o processo de produção rural do pão de milho, uma vez que fora parte ativa, em colaboração com a sua avó, num forno a lenha em casa dos avós (uma casa tradicional minhota restaurada, que conta também com os tradicionais espigueiros). Por esta razão, disse que gostou especialmente da alusão à avó, e ainda da alusão às cerejas. Identificou-se também com o momento em que o menino subia ao telhado, recordando-lhe momentos passados com o seu irmão, novamente em casa dos avós. Conhecia ainda, embora muito vagamente, o processo de produção do linho, uma vez que já vira alguns dos instrumentos envolvidos. Em contrapartida, o Leonardo relatou na entrevista que não conhecia as etapas deste último processo, embora os pais fossem oriundos de meios rurais. Contudo, disse que gostou bastante de as conhecer e comentou que o compositor captara bem as várias fases.

\section{DISCUSSÃO}

O presente projeto de investigação pretendeu compreender os efeitos do recurso aos elementos extramusicais do Minho na abordagem de repertório contemporâneo português no ensino individual de piano. Os resultados foram analisados em torno de dois eixos fundamentais: a metáfora no ensino da música e a contextualização cultural.

Em relação ao primeiro eixo de interpretação, os resultados parecem trazer à tona o poder da metáfora no ensino da interpretação musical em três frentes. Do geral para o particular, a primeira frente respeita à compreensão (ou talvez fruição, apreciação) da linguagem musical contemporânea, assumindo a metáfora uma função de mediação técnica, tal qual o comentário nas apresentações públicas de música contemporânea (Albèra, 2007). Pelo facto dos seus percursos serem relativamente áridos no que toca aos mediadores intelectuais desta linguagem, os alunos apoiaram-se noutros elementos - mais ou menos conhecidos, pertencentes a outros campos sensitivos - para apreender o discurso, descobrindo afinal que a primeira impressão não correspondia ao que, decorrido algum tempo, sentiam quando tocavam e ouviam a obra.

A segunda frente reporta-se à compreensão holística da peça, isto é, à capacidade de olhar para a peça como um todo. Os elementos extramusicais cimentaram os vários "ingredientes" da obra, interligando-os num corpo e forma consistentes. Esta compreensão holística tem intensas repercussões na performance musical - que ocorre num determinado espaço temporal, efémero - pois permite ver o caminho, ver a história que se conta para além das palavras que são ditas naquele momento específico. A forma abre espaço à expressividade, ao risco, manifesto aqui no à-vontade das apresentações públicas finais.

Por fim, a terceira frente concerne à execução dos vários motivos musicais das peças, que assistiu a uma evolução graças ao efeito dos elementos extramusicais. Parece confirmar-se o potencial da metáfora enquanto ferramenta privilegiada de transmissão, talvez por conseguir "ir além do tangível” (Schippers, 2006, p. 214), sem uma solução absolutamente clara. No campo musical, as palavras que descrevem o som e as suas oscilações encontrarão necessariamente auxílio no recurso estilístico da 
metáfora. Por isso, muitos dos elementos eram próximos de expressões comuns na comunicação vocabular própria da interpretação musical. Contudo, pela análise das variações da eficácia dos elementos, torna-se necessário adequar a metáfora ao desenvolvimento e maturidade do aluno (Schippers, 2006), sob pena de esta se lhe revelar absolutamente obscura.

Quanto ao segundo eixo, relativo ao significado cultural e à identificação com os elementos minhotos, os casos variaram, uma vez mais. Com a Isolda, pôde-se verificar que, para além do envolvimento comunitário, houve uma aproximação a realidades e experiências concretas vividas em casa dos seus avós, com a sua avó e com o seu irmão, indicando a presença de uma contextualização curricular a partir do local (Fernandes et al., 2013). Por outro lado, no caso do Leonardo, apesar de haver uma contextualização cultural, no sentido em que tomou contacto com elementos culturais da região e relativamente familiares aos seus pais, provenientes do meio rural, não houve uma contextualização curricular, uma vez que esses elementos se distanciavam das experiências do aluno.

De qualquer modo, mesmo não havendo contextualização curricular no caso do Leonardo, a contextualização cultural, na forma de elementos extramusicais minhotos, parece consubstanciar um meio original de levar os alunos a conhecer costumes da sua cultura regional. À semelhança de outros projetos realizados de integração curricular de música tradicional portuguesa, embora nem sempre haja contacto direto com o elemento especificamente local, a sua integração curricular permite que os alunos descubram e atribuam valor a um legado que, geracionalmente, não lhes é assim tão distante.

\section{CONCLUSÃO}

Em primeiro lugar, será oportuno ressalvar aqui o papel da imaginação (no seu sentido lato) enquanto integrante fundamental da interpretação musical, capaz de promover uma autoemancipação (de dentro para dentro) do intérprete, uma vez que este reivindica para si o mundo espiritual da obra, neste caso inspirado nas ideias do compositor. A integração da imaginação na interpretação musical foi especialmente relevante no caso da Isolda, tanto durante o estudo em casa como na apresentação final.

Contudo, importa também reconhecer as limitações do estudo, afunilado apenas a dois casos, num contexto de prática supervisionada naturalmente condicionado por uma variedade de fatores (programas da escola, tempo, entre outros). Admite-se também que o parecer do público (que não foi consultado), mais especificamente dos pais (cujas opiniões apenas se souberam por intermédio dos alunos), teria sido de interessante análise neste projeto.

Por fim, não se poderá deixar de afirmar que contextualização cultural - relativo à comunidade e ao local - não é sinónimo de contextualização curricular em tempos de globalização intensa. As práticas locais ocorrem simultaneamente às globais, num espaço comum. Na cidade de Braga, devido a um êxodo rural pós-25 de abril, confrontam-se gerações predominantemente provenientes de meios rurais e gerações predominantemente provenientes de meios urbanos (as mais jovens). Encontrar um ponto comum entre contextualização cultural e contextualização curricular, valorizando-se o meio local em simultâneo com as experiências e vivências dos alunos, não 
parece ser fácil. Fica o desafio lançado para futuros projetos no ensino do instrumento.

\section{REFERÊNCIAS}

Albèra, P. (2007). Le Son et le sens: Essais sur la musique de notre temps. Nova edição (online). Edições Contrechamp. http://10.4000/books.contrechamps.1451

Bates, V. C. (2014). Rethinking Cosmopolitanism in Music Education.

Action, Criticism \& Theory for Music Education, 13(1).

https://s3.amazonaws.com/academia.edu.documents/37762544/ACT_Mar2014_310to 327.pdf?ASAccessKeyld=AKIAIWOWYYGZ2Y53UL3A\&Expires $=1559085406 \&$ Signatur e=UZohjxYto7tj54JJfXYwGL4oc\%3D\&responsecontentdisposition=inline\%3Bfilename \%3DRethinking_Cosmopolitanism_in_Music_Educ.pdf

Bernardo, A. (2010). O Ciclo do Linho. https://www.saberfazer.org/research/2010/07/11/o-linhal.

Brito, H., \& Vieira, M. H. (2014). Sargaceiros de Apúlia e orquestra de cordas: contributos para uma etnopedagogia musical. Revista Música Hodie, GoiâNia, 14(2), 99-110. http://repositorium.sdum.uminho.pt/handle/1822/52429.

Carvalho, M. (2010). Fernando Lopes Graça. In S. Castelo-Branco (Ed.), Enciclopédia da Música em Portugal no Século XX. Círculo de Leitores.

Cruz, C. (1998). Sobre Kodály e o seu conceito de educação musical: Abordagem geral e indicações bibliográficas. Revista Associação Portuguesa de Educação Musical, 98.

https://repositorio.ipl.pt/bitstream/10400.21/1458/1/kodaly_1998.pdf.

Clarke, V., \& Braun, V. (2015). Thematic Analysis. In E. Lyons \& A. Coyle (Eds.), Analysing qualitative data in Psychology. SAGE Publications.

Dias, A. (2019). Lume de chão: Tecido de memórias e afectos. Edições

mpmp.

Publishing.

Dillon, S. (2007). Music, Meaning and transformation. Cambridge Scholars

Fernandes, P., Leite, C., Mouraz, A., \& Figueiredo, C. (2013). Curricular contextualization: Tracking the meanings of a concept. The Asia-Pacific Educational Researcher, 22(4). https://doi.org/10.1007/s40299-012-0041-1.

Freire, P. (1986). Pedagogia da Autonomia. Paz e Terra.

Foucault, M., Boulez, P., \& Rahn, J. (1985). Contemporary music and the public. Perspectives of New Music, 24(1), 6-12. http://www.jstor.org/stable/832749.

Graça, F. L. (1989). Decadência?; A crise da música portuguesa; Necessidade e capricho na música portuguesa contemporânea. In F. L. Graça, $A$ música portuguesa e os seus problemas, vol. 2. Caminho.

education. Ashgate.

Green, L. (2002). How popular musicians learn: A way ahead for music Luísa Faria). Gradiva.

Grout, D., \& Palisca, C. (1988). História da Música Ocidental (Trad.: Ana

Lobos, H. (2010). Educação musical: presença de Villa-Lobos. A formação da consciência musical brasileira. In M. Carvalho (Ed.), Heitor Villa-Lobos. MEC/ Fundação Joaquim Nabuco/ Editora Massangana.

Moreira, C. (2006). O entendimento do Património no contexto local. Oppidum, 1, 127-140. https://www.cmlousada.pt/cmlousada/uploads/document/file/246/23_original.pdf.

Palheiros, G. (1999). Investigação em educação musical: Perspetivas para o seu desenvolvimento em Portugal. Revista Música, Psicologia E Educação, 1. https://doi.org/10.26537/rmpe.v0i1.2392 
Ribeiro, A. (2017). pareSeres da terra e a música popular portuguesa no Conservatório do Vale do Sousa. Revista Vórtex, 5(3), 1-20.

Ruiz, J., \& Vieira, M. H. (2017). Cantem como se estivessem num prado verde, com ar fresco no rosto... - Imagética e metáfora na pedagogia coral infantil. Revista E-Psi, 7(Suplm.1), 3-17. http://repositorium.sdum.uminho.pt/bitstream/1822/52332/1/Ruiz e Vieira_Revista EPsi 2017.pdf

Santos, B. (1993). Modernidade, identidade e a cultura de fronteira. Revista Sociologia USP, 5(1-2), 31-52.

http://www.boaventuradesousasantos.pt/media/Modernidade Identidade Fronteira_TempoSocial1994.pdf.

Schippers, H. (2006). 'As if a little bird is sitting on your finger...': metaphor as a key instrument in training. International Journal of Music Education, 24(3), 209-217. https://www.researchgate.net/publication/29464684_'As_if_a_little_bird_is_sitting_on_ your_finger'_Metaphor_as_a_key_instrument_in_training_professional_musicians.

Spring, J. (2016). The Power of Metaphor in Rural Music Education Research. Action, Criticism, and Theory for Music Education, 15(4), 76-103. https://doi.org/10.22176/act15.4.76

Vargas, A. (2007). A ausência da música portuguesa no contexto europeu : Uma investigação em curso. Revista Crítica de Ciências Sociais, 78, 47-69. https://doi.org/10.4000/rccs.754.

Wade, J. (2017). Metaphor and the shaping of educational thinking. In F. Ervas, E. Gola \& M. G. Rossi (Eds.), Metaphor in Communication, Science and Education (pp. 305-319). De Gruyter Mouton. https://doi.org/10.1515/9783110549928-001

Winter, R. (2003). Global media, cultural change and the transformation of the local: The contribution of cultural studies to a sociology of hybrid formations. In U. Beck, N. Sznaider \& R. Winter (Eds.), Global America? - The cultural consequences of globalization. Liverpool University Press.

Wolfe, J. (2019). An investigation into the nature and function of metaphor in advanced music instruction. Research Studies in Music Education, 41(3), 280-292. https://doi.org/10.1177/1321103X18773113 
Informação dos autores:

i Escola Artística de Dança do Conservatório Nacional, Portugal.

https://orcid.org/0000-0002-3729-1193

ii CEHUM, Universidade do Minho, Portugal.

https://orcid.org/0000-0001-6370-3211

iii CEHUM, Universidade do Minho, Portugal.

https: //orcid.org/0000-0002-7885-1046

Toda a correspondência relativa a este artigo deve ser enviada para:

Isabel Romero

Rua Maria Pia 218, 1350-197 Lisboa.

romeroisabel94@gmail.com

Recebido em 14 de janeiro de 2021

Aceite para publicação em 23 de junho de 2021 


\title{
Evoking extra-musical elements from Minho in the piano lesson: Contemporary Portuguese repertoire in context
}

\begin{abstract}
The present case study aimed to explore the possible advantages of using extra-musical elements from the region of Minho in the pedagogical approach of contemporary Portuguese repertoire, in an official music school located in that region. To avoid the decontextualization of the music school, the project aimed to unite the European element to the national element and, above all, to the local element, through modern sounds contextualized by the extra-musical meanings which inspired the composition. Following an action research framework, two participant students of the secondary level were asked to study musical pieces, which evocated elements from Minho, of the contemporary Portuguese composer Amílcar Vasques-Dias. Combined with case study methodologies, the project involved a detailed observation of the learning process of those musical pieces. The methodology included: (1) a musical analysis focused on extra-musical elements and (2) an action implementation, with classes focused on the establishment of bridges between the musical and the extra-musical elements and a final concert. The results indicated that the extra-musical elements promoted the 'understanding' (or appreciation) of contemporary musical language, thus playing a role of technical mediation, interpreted according to Albèra (2007). Besides, they contributed to the improvement of several performative aspects, at the technical and musical levels. On the other hand, the use of these elements helped to promote the local culture. In one case, those elements were familiar to the student's personal experiences, constituting thus an example of curricular contextualization.
\end{abstract}

\footnotetext{
Keywords: Contemporary Portuguese repertoire; Extra-musical references; Cultural meaning; Curricular contextualization; Metaphor in teaching
} 


\section{Évoquant des éléments extramusicaux du Minho dans le cours de piano: Répertoire contemporain portugais en contexte}

\section{RÉSUMÉ}

L'étude de cas présentée a eu pour but d'explorer les avantages possibles de l'utilisation d'éléments extramusicaux de la región du Minho dans l'approche pédagogique du répertoire portugais contemporain, dans une école officielle de musique située dans cette région. Afin d'éviter la décontextualisation de l'école de musique, étrangère à son lieu et à son époque, le projet a cherché à unir l'européen, le national et surtout le local, entre sonorités modernes contextualisés par les significations extramusicales qui ont servi d'inspiration à la composition. Dans un cadre de recherche-action, il a été demandé à deux élèves du secondaire d'étudier des pièces pour piano évocatrices d'éléments du Minho du compositeur portugais contemporain Amílcar Vasques-Dias. Combiné avec des méthodologies d'étude de cas, le projet a impliqué une observation détaillée du processus d'apprentissage de ces pièces musicales. La méthodologie a compris (1) une analyse musicale axée sur des éléments extramusicaux, pour la planification et (2) des cours basés sur l'intersection entre le musical et l'extramusical et un concert final, pour l'intervention. Les résultats ont indiqué que les éléments extramusicaux ont favorisé la «compréhension» (ou l'appréciation) du langage musical contemporain chez les étudiants interventionnels, jouant ainsi un rôle de médiation technique, interprété selon Albèra (2007). De plus, ils ont contribué à l'amélioration des aspects techniques, interprétatifs et expressifs. D'autre part, l'utilisation de ces éléments a contribué à promouvoir l'appréciation de la culture régionale. Enfin, les éléments du Minho se sont rapprochés des expériences personnelles de l'une des étudiants, constituant ainsi un cas de contextualisation curriculaire.

Mots-clés: Repertoire contemporain portugais; Références extramusicales; Signification culturelle; Contextualisation curriculaire; Métaphore dans l'enseignement 